\title{
Prevalence of Hypothyroidism in a Large Sample of Patients with Obesity Hypoventilation Syndrome
}

This article was published in the following Dove Press journal:

Nature and Science of Sleep

\author{
Ahmed S BaHammam (iD ${ }^{1,2}$ \\ Salih Aleissi $\mathbb{D}^{\prime}$ \\ Awad H Olaish (D) \\ Aljohara S Almeneessier (D) I,3 \\ Anwar A Jammah (D) ${ }^{4}$ \\ 'University Sleep Disorders Center, \\ College of Medicine, King Saud \\ University, Riyadh, Saudi Arabia; \\ ${ }^{2}$ Strategic Technologies Program of the \\ National Plan for Sciences and \\ Technology and Innovation in the \\ Kingdom of Saudi Arabia, Riyadh, Saudi \\ Arabia; ${ }^{3}$ Family and Community \\ Medicine, College of Medicine, King Saud \\ University, Riyadh, Saudi Arabia; \\ ${ }^{4}$ Endocrinology Unit, Thyroid Diseases \\ Section, Department of Medicine, King \\ Saud University, Riyadh, Saudi Arabia
}

Correspondence: Ahmed S BaHammam University Sleep Disorders Center,

College of Medicine, King Saud University,

Box 225503, Riyadh II 324, Saudi Arabia

Tel +966- I I-467-9495

Fax +966-I I-467-9179

Emails ashammam2@gmail.com

Aljohara S Almeneessier

Family and Community Medicine, College of Medicine, King Saud University, Riyadh, Saudi Arabia

Tel +966- I I-467-9495

Fax +966-I I-467-9179

Email aljoharas@yahoo.com
Purpose: Data on hypothyroidism in patients with obesity hypoventilation syndrome (OHS) are scarce. This study assessed the prevalence of hypothyroidism among a large group of patients with OHS.

Patients and Methods: This was a prospective observational study of 308 consecutive patients with OHS seen between January 2002 and December 2018. Serum thyroid-stimulating hormone (TSH) and free-thyroxine (FT4) levels were measured in all patients. The OHS patients were compared with 445 patients with obstructive sleep apnoea (OSA) matched for age, sex, and body mass index (BMI).

Results: The OHS patients had a mean age of $55.1 \pm 13.8$ years and a BMI of $43.9 \pm 14.8$ $\mathrm{kg} / \mathrm{m}^{2}$; apnoea hypopnea index was $\geq 30$ events $/ \mathrm{hr}$ in $222(72 \%)$. Clinical hypothyroidism was diagnosed in $58(18.8 \%)$ of the OHS patients; only two cases $(0.6 \%)$ were diagnosed in the sleep disorders clinic (newly diagnosed cases). Subclinical hypothyroidism was diagnosed in $19(6.2 \%)$ of the OHS patients based on elevated TSH and normal FT4 levels; all cases were newly diagnosed. A logistic regression model identified female sex as the only predictor of clinical hypothyroidism in OHS patients (odds ratio: 2.801 [1.386-5.662], $\mathrm{p}=$ 0.004). There was no significant difference in clinical hypothyroidism prevalence between the OHS and OSA patients; however, subclinical hypothyroidism was more common in OHS than in OSA patients $(6.2 \%$ vs $2.9 \%$, respectively, $\mathrm{p}=0.03)$.

Conclusion: Clinical hypothyroidism was prevalent among patients with OHS; however, newly diagnosed cases of clinical hypothyroidism were relatively low. Female sex was the only predictor of clinical hypothyroidism.

Keywords: menopause, obstructive sleep apnoea, subclinical hypothyroidism, TSH, thyroxine

\section{Introduction}

Thyroid disease is a global medical problem that can have a significant impact on health and well-being. Hypothyroidism is a relatively common medical problem, which is much more common among women compared to men. ${ }^{1}$ Hypothyroidism may present in a subclinical form or as an overt hypothyroidism state. ${ }^{2}$ Hypothyroidism has been linked to several comorbidities involving different organs, including the respiratory and cardiovascular systems. ${ }^{3,4}$

Hypothyroidism may affect several functions of the respiratory system and breathing control. ${ }^{3}$ It may reduce the central respiratory drive, cause respiratory muscle weakness, and increase the risk of sleep-related breathing disorders (SBDs). ${ }^{5-7}$

Thyroxine hormone replacement does not always cure SBDs, and SBD treatment will not cure hypothyroidism. ${ }^{8}$ Therefore, both disorders need to be diagnosed and treated concomitantly. 
A few studies have assessed the prevalence of hypothyroidism among patients with obstructive sleep apnoea (OSA) and reported conflicting results. ${ }^{9,10}$ However, data on hypothyroidism in obesity hypoventilation syndrome (OHS) patients are scarce. In a recent study that aimed to assess gender differences in OHS, the prevalence of hypothyroidism was reported to be $20 \%{ }^{11}$ The prevalence among men and women was $24.5 \%$ and $8.3 \%$, respectively. ${ }^{11}$ The hypothyroid state represses responses to hypoxic, ${ }^{12}$ hypercapnic, ${ }^{5}$ and ventilatory stimuli, which theoretically could predispose obese individuals to OHS. ${ }^{10}$ Therefore, it is important to investigate the association between hypothyroidism and OHS.

To the best of our knowledge, no study has been designed to specifically assess the prevalence of hypothyroidism in OHS patients. Therefore, this study aimed to determine the prevalence of hypothyroidism based on thyroid-stimulating hormone (TSH) and free thyroxine (FT4) levels among a large group of OHS patients and to identify the characteristics and predictors of hypothyroidism in OHS patients.

\section{Patients and Methods}

This was a prospective observational study, which was a part of a large project to prospectively collect data to evaluate OHS and its comorbidities. ${ }^{11,13}$ Consecutive patients with OHS who were referred to the University Sleep Disorders Centre (USDC) at King Saud University Medical City at King Saud University between January 2002 and December 2018 with suspected SDB were included. Exclusion criteria encompassed patients with congestive heart failure, chronic neurological, muscular, or respiratory diseases, wall and thoracic vertebral column deformities, and patients on sedative drugs. Full clinical evaluations, including detailed medical history and physical examination, were performed by a sleep medicine specialist. Data about comorbid conditions were obtained by medical history or from the medical records of the patients.

The protocol in the USDC entails performing arterial blood gas (ABG) analysis, spirometry, and thyroid function tests (TSH and FT4) for patients with SBD. Daytime sleepiness was assessed using the Epworth Sleepiness Scale. ${ }^{14}$

The prevalence of thyroid disease in the OHS patients was compared with that of OSA patients who were referred during the same study period and matched for age, sex, and body mass index (BMI) $(\mathrm{n}=445)$.
The study protocol was approved by the institutional review board (IRB) in the College of Medicine at King Saud University and Medical City, and written informed consent was obtained for all participants. All referred patients consented to join the study as there were no interventions.

\section{Medical and Physiological Evaluation}

All patients had spirometry performed according to the ATS/ERS task force guidelines using a MasterScreen (Erich Jaeger ${ }^{\circledR}$ GmbH \& Co KG, Würzburg, Germany). ${ }^{15}$ Additionally, blood samples for ABGs were taken while the patient was awake, sitting, and breathing room air after resting for $15 \mathrm{~min}$. ABGs were measured using a $\mathrm{GEM}^{\circledR}$ Premier ${ }^{\mathrm{TM}} 4000$ analyser (Instrumentation Laboratory, Lexington, MA, USA).

As per protocol, a blood sample for FT4 and TSH measurement was collected in the morning within four weeks of the diagnostic polysomnography. The electrochemiluminescence immunoassay method ${ }^{16}$ (Roche Diagnostics GmbH, Mannheim, Germany) was used to measure hormone levels. The normal reference levels for FT4 and TSH are 10.3-25.8 pmol/L and $0.25-5.0 \mu \mathrm{IU} / \mathrm{mL}$, respectively. For patients with an elevated serum TSH level, a repeat measurement of both serum TSH and FT4 was performed after 2-3 months, and the initial findings were confirmed.

Clinical hypothyroidism was diagnosed when one of the following conditions was met: (1) patients with known clinical hypothyroidism who were on thyroxine replacement at the time of referral to the sleep clinic; (2) the laboratory criteria for clinical hypothyroidism were met, which included a TSH level of $>5.0 \mu \mathrm{IU} / \mathrm{mL}$ and a FT4 level of $<10.3 \mathrm{pmol} / \mathrm{L}$ (newly diagnosed cases). Subclinical hypothyroidism was diagnosed if the FT4 level was within the normal range, but the TSH level was $>5.0 \mu \mathrm{IU} / \mathrm{mL}^{17}$

Postmenopausal status was diagnosed after a woman had experienced 12 consecutive months without menstruation. ${ }^{18}$

\section{Polysomnography}

All referred patients with suspected SBD undertook a standard level I overnight attended polysomnography (PSG) using the Alice ${ }^{\circledR}$ diagnostic equipment (Philips, Respironics Inc., Murrysville, PA, USA). Manual scoring of the raw data was done following scoring criteria of the American Academy of Sleep Medicine. ${ }^{19}$ The adopted 
definition of the desaturation index was $\geq 3 \%$ decrease in oxygen saturation from the pre-event baseline. The scorers of the sleep studies were blind to the results of the thyroid function test.

\section{OHS and Diagnoses}

OHS and OSA were diagnosed following the International Classification of Sleep Disorders-Third Edition (ICSD-3) criteria. $^{20}$

\section{Statistical Analysis}

The numerical data are presented in the text and tables as mean and standard deviation (SD). For two-group comparison of continuous variables, Student's $t$-tests were used when the normality test was met. Otherwise, the MannWhitney $U$-test was used. For dichotomous data, the chisquare test was utilised.

To identify the independent predictors of clinical and subclinical hypothyroidism, an initial analysis was performed using a univariate logistic regression model where one explanatory factor was examined at a time. Then, if factors with significant $p$-values were identified in the univariate analysis, a multivariate logistic regression model was performed for those variables. Statistical significance was set at $p<0.05$. The SPSS software (version 22; Chicago, IL, USA) was used for the analyses.

\section{Results}

\section{Description of Subjects}

A total of 4940 patients $(64 \%$ men) were referred to the USDC with a clinical suspicion of SBD for overnight PSG during the study period. All patients were assessed by a member of the team before undergoing overnight sleep studies. Among them, 4317 (87.4\%) had SDB (2644 men and 1673 women); of which, 4009 (63\% men) were normocapnic (pure OSA), and 308 patients (198 women and 110 men) had OHS (Figure 1).

Therefore, 308 OHS patients (64\% women) with a mean age of $55.1 \pm 13.8$ years and a BMI of $43.9 \pm 14.8$ $\mathrm{kg} / \mathrm{m}^{2}$ were evaluated; $222(72 \%)$ had an apnoea hypopnoea index of $\geq 30$ events/hr. Pulmonary function parameters revealed FEV1/FVC (\%) of $84.9 \pm 9.1, \mathrm{PaCO} 2$ of $53 \pm 9.2 \mathrm{mmHg}, \mathrm{PaO} 2$ of $66.6 \pm 18.3 \mathrm{mmHg}$, and $\mathrm{HCO} 3$ of $31.1 \pm 5.5 \mathrm{mmol} / \mathrm{L}$

\section{Thyroid Disease Among Subjects}

Among patients with $\mathrm{OHS}$, the TSH levels ranged from 1.1 to $34.4(3.3 \pm 3.2) \mu \mathrm{IU} / \mathrm{mL}$ and the FT4 levels ranged from 0.6 to $24.3(15 \pm 2.9) \mathrm{pmol} / \mathrm{L}$. Clinical hypothyroidism was diagnosed in $58(18.8 \%)$ of the OHS patients. Only two of these patients had hypothyroidism diagnosed in the sleep disorders clinic (newly diagnosed cases, $0.6 \%$ overall). The remaining patients already had

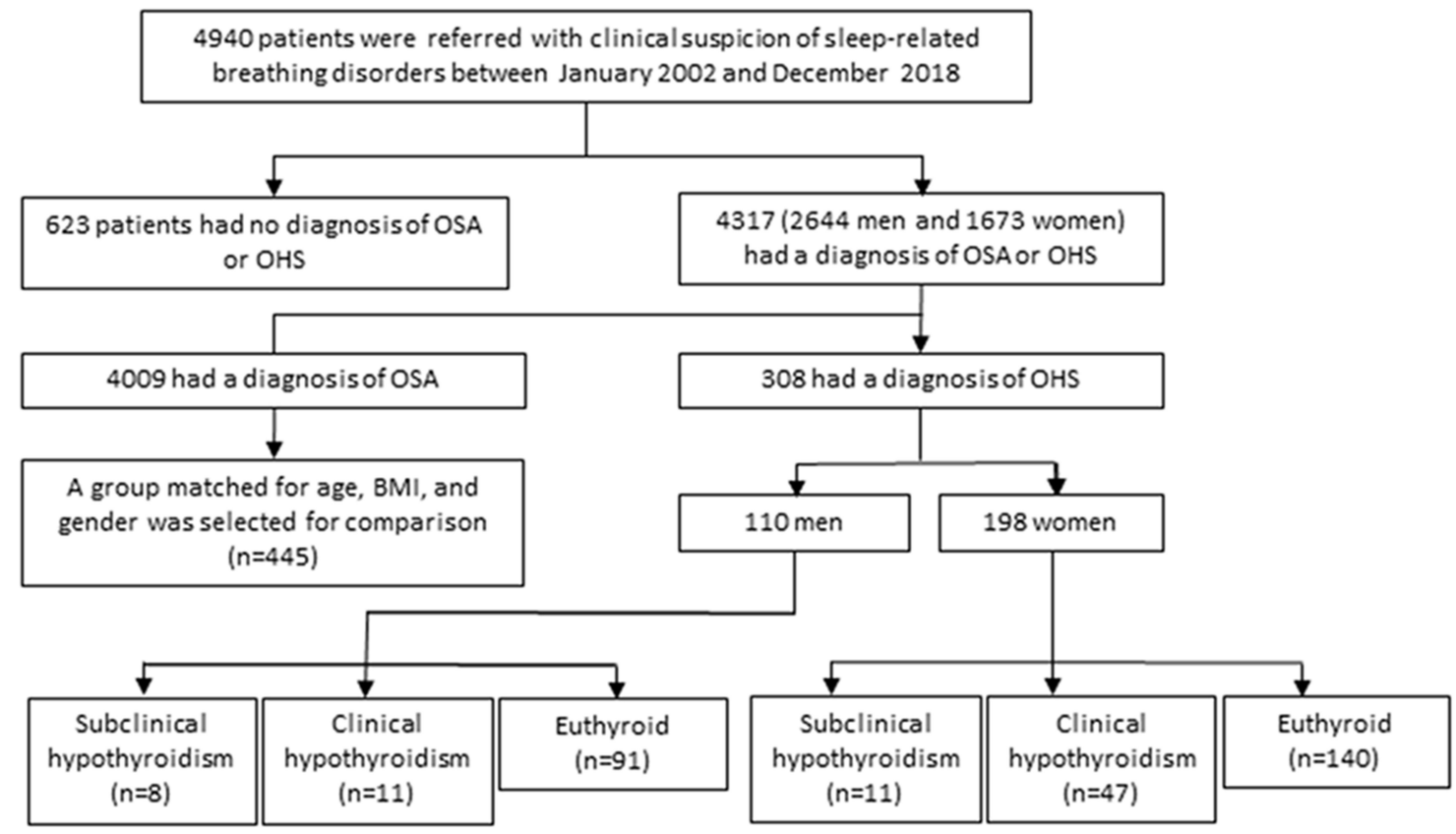

Figure I Study population flow chart.

Abbreviations: OSA, Obstructive sleep apnoea; OHS, obesity hypoventilation syndrome; BMI, body mass index. 
hypothyroidism diagnosed and had been on thyroxine replacement therapy. Subclinical hypothyroidism was diagnosed in $19(6.2 \%)$ of the OHS patients based on elevated TSH and normal FT4 levels. All of them were newly diagnosed. No cases of hyperthyroidism were diagnosed.

Table 1 presents the demographics and PSG parameters of the OHS patients with and without clinical

Table I Demographics and Polysomnography Data of Obesity Hypoventilation Syndrome Patients with and without Clinical Hypothyroidism

\begin{tabular}{|c|c|c|c|}
\hline \multirow[t]{3}{*}{ Variables } & \multicolumn{2}{|c|}{ Mean \pm SD/n (\%) } & \multirow[t]{3}{*}{$P$-value } \\
\hline & \multicolumn{2}{|c|}{ Clinical Hypothyroidism } & \\
\hline & Yes $(n=58)$ & No $(n=250)$ & \\
\hline Age (years) & $54.9 \pm 14.6$ & $55.1 \pm 13.7$ & 0.9 \\
\hline Female sex & $47(8 I)$ & $15 \mid(60.4)$ & 0.003 \\
\hline Body mass index $\left(\mathrm{kg} / \mathrm{m}^{2}\right)$ & $45.1 \pm 11.3$ & $43.7 \pm 15.5$ & 0.29 \\
\hline Neck circumference (inches) & $15.9 \pm 1.7$ & $15.9 \pm 1.6$ & 0.99 \\
\hline Waist circumference (inches) & $46.8 \pm 10.5$ & $48.7 \pm 7.1$ & 0.89 \\
\hline Hip circumference (inches) & $53.4 \pm 7.8$ & $5 \mathrm{I} .1 \pm 7.3$ & 0.1 \\
\hline Epworth Sleepiness Scale & $10.6 \pm 6.1$ & $10.4 \pm 5.8$ & 0.7 \\
\hline $\mathrm{pH}$ & $7.4 \pm 0$ & $7.4 \pm 0.1$ & 0.3 \\
\hline $\mathrm{PaCO} 2(\mathrm{mmHg})$ & $53 \pm 9.1$ & $53 \pm 9.2$ & 0.9 \\
\hline $\mathrm{PaO} 2(\mathrm{mmHg})$ & $64.7 \pm 15$ & $67.1 \pm 19$ & 0.5 \\
\hline $\mathrm{HCO} 3(\mathrm{mmol} / \mathrm{L})$ & $31.4 \pm 4.7$ & $31 \pm 5.6$ & 0.6 \\
\hline Haemoglobin level $(g / L)$ & $129.2 \pm 26.5$ & $134.6 \pm 23.3$ & 0.1 \\
\hline Haematocrit & $40.1 \pm 5.7$ & $40.3 \pm 6.9$ & 0.9 \\
\hline Thyroid-stimulating hormone & $5.1 \pm 5.7$ & $2.8 \pm 1.9$ & 0.006 \\
\hline FT4: Free thyroxine & $15.1 \pm 3.9$ & $14.9 \pm 2.7$ & 0.2 \\
\hline \multicolumn{4}{|l|}{ Smoker } \\
\hline Smoker & $2(3.4)$ & $13(5.2)$ & 0.7 \\
\hline X-Smoker & $3(5.2)$ & $19(7.6)$ & \\
\hline Postmenopausal women & $36(77)$ & $128(84.8)$ & 0.1 \\
\hline \multicolumn{4}{|l|}{ Comorbidities } \\
\hline Hypertension & $38(65.5)$ & $167(66.8)$ & 0.8 \\
\hline Ischaemic heart disease & $6(10.3)$ & $33(13.2)$ & 0.5 \\
\hline Diabetes mellitus & $34(58.6)$ & $123(49.2)$ & 0.2 \\
\hline Renal failure & $5(8.6)$ & $14(5.6)$ & 0.4 \\
\hline Stroke & $0(0)$ & $3(1.2)$ & 1.000 \\
\hline Bronchial asthma & $26(44.8)$ & $88(35.2)$ & 0.2 \\
\hline Hypercholesterolemia & $25(43.1)$ & $85(34)$ & 0.3 \\
\hline \multicolumn{4}{|l|}{ Polysomnographic findings } \\
\hline Sleep efficiency (\%) & $62.9 \pm 21$ & $64.3 \pm 22$ & 0.5 \\
\hline $\mathrm{AHI}$ (events/hr) & $69.2 \pm 42.1$ & $65.2 \pm 44.9$ & 0.4 \\
\hline AHI-NREM ${ }^{\ddagger}$ (events/hr) & $69.7 \pm 43.4$ & $64 \pm 47.1$ & 0.3 \\
\hline AHI-REM ${ }^{\S}$ (events/hr) & $52.1 \pm 40.1$ & $61 \pm 39.7$ & 0.3 \\
\hline $\mathrm{AHI} \geq 30$ & $45(77.6)$ & $177(70.8)$ & 0.3 \\
\hline Desaturation index (desaturations/hr) & $50.1 \pm 44$ & $49 \pm 42.4$ & 0.9 \\
\hline Time with $\mathrm{SpO} 2<90 \%(\mathrm{~min})$ & $45.8 \pm 42.2$ & $42 \pm 39.7$ & 0.6 \\
\hline Lowest recorded SpO2 (\%) & $70.4 \pm 19.9$ & $70.5 \pm 17.9$ & 0.7 \\
\hline Mean nocturnal SpO2 (\%) & $87.6 \pm 11.2$ & $88.4 \pm 9$ & 1.0 \\
\hline Arousal index (arousals/hr) & $64.1 \pm 39.3$ & $64.6 \pm 41.5$ & 0.9 \\
\hline
\end{tabular}

Abbreviations: *AHI, apnoea hypopnoea index; ${ }^{\ddagger} \mathrm{AHI}-\mathrm{NREM}$, non-rapid eye movement apnoea hypopnea index; ${ }^{\S} \mathrm{AHI}-\mathrm{REM}$, non-rapid eye movement apnoea hypopnea index. 
hypothyroidism. Women represented $81 \%$ of the patients with clinical hypothyroidism.

Clinical hypothyroidism was present in 47 women $(23.7 \%)$ compared to 11 men $(10 \%) \quad(p=0.006)$. Subclinical hypothyroidism was present in 11 women $(7.3 \%)$ compared to 8 men $(8.2 \%)(p=0.3)$. Table 2 shows the within-gender comparisons between the euthyroid OHS patients and the OHS patients with clinical and subclinical hypothyroidism. Women with clinical hypothyroidism were significantly younger than euthyroid women $(56.6 \pm 13.6$ years vs $60.6 \pm 11.2$ years, respectively, $\mathrm{p}<0.05$ ). On the other hand, men with subclinical hypothyroidism had significantly higher waist circumference compared to those for euthyroid and hypothyroid men $(55.1 \pm 12.2$ vs $48.9 \pm 7$ and vs $47.7 \pm 6.9$ inches, respectively, $p<0.05$ ). Premenopausal status was more common in women with clinical hypothyroidism than euthyroid women $(15 \%$ vs 25.5\%); however, the difference did not reach statistical significance, $p=015$ ). The BMI was also nonsignificantly higher in men with subclinical hypothyroidism than in euthyroid men or men with clinical hypothyroidism.

Table 3 shows a gender-based comparison between those with and without clinical hypothyroidism. Women with euthyroidism were older and had a higher BMI and had a lower $\mathrm{PaO} 2$ and a higher $\mathrm{PaCO} 2$ and $\mathrm{HCO} 3$ than euthyroid men. Additionally, hypertension, diabetes mellitus, bronchial asthma, and hypercholesterolemia were more common in euthyroid women than in euthyroid men. In patients with clinical and subclinical hypothyroidism, there were no significant differences between the genders.

A logistic regression model identified female sex as the only predictor of clinical hypothyroidism in OHS patients (odds ratio: 2.801 [1.386-5.662], $\mathrm{p}=0.004$ ).

\section{Comparison with OSA}

As thyroid hormones levels are related to age, BMI, and gender, the OHS patients were compared with OSA patients referred during the study period $(n=445)$ who were matched to the OHS patients for age, sex, and BMI (Table 4). There was no difference between the two groups in clinical hypothyroidism prevalence; however, subclinical hypothyroidism was more common among OHS than OSA patients $(19(6.2 \%)$ vs.13 $(2.9 \%)$, respectively, $\mathrm{p}=$ 0.030 ).

\section{Discussion}

This large cohort of OHS patients displayed a high prevalence of hypothyroidism, particularly in women. In the
OHS patients, the prevalence of clinical hypothyroidism was $18.8 \%$ and the prevalence of subclinical hypothyroidism was $6.2 \%$. All cases of subclinical hypothyroidism were newly diagnosed, whereas only two cases of clinical hypothyroidism were newly diagnosed.

It had been previously proposed that hypothyroid status increases upper airway narrowing and suppresses hypoxic, ${ }^{12}$ and hypercapnic ventilatory responses, ${ }^{5}$ which theoretically could increase the predisposition of obese patients to OSA, which may progress to OHS. ${ }^{11}$ The upper airway and mainly the pharynx may become narrowed as a result of the soft tissue infiltration that occurs in hypothyroidism. ${ }^{10}$ It has been shown that mucopolysaccharides and proteins infiltrate the tongue producing enlargement and infiltrate the neck's soft tissues, which may enhance upper airway narrowing resulting in upper airway obstruction. ${ }^{21-23}$ On top of that, hypothyroidism may modify the myosin heavy chain profile, particularly in the genioglossus muscle, which causes dysfunction of the muscle. ${ }^{24}$ Nevertheless, hypothyroidism did not predict OSA, by itself, and is not an independent predictor of OSA independent of age, BMI, or sex. ${ }^{25}$ In animal models, hypothyroidism causes a decrease in peripheral chemoreceptor response to hypoxia and hypercapnia. ${ }^{26}$ In humans, it has been shown that almost $30 \%$ of patients with hypothyroidism have a reduced ventilatory response to hypoxia/hypercapnia. ${ }^{5,12,27}$ Female sex has been identified as a predictor of blunted ventilatory response in patients with hypothyroidism. ${ }^{28}$ However, the diminished ventilatory response has been linked with clinically overt severe hypothyroidism, such as cases of myxedema and severe hypothyroidism (thyroid ablation); severe hypothyroidism patients were reported to have a reduced hypoxic ventilatory drive that was reversible with hormonal replacement therapy. ${ }^{12}$ On the other hand, weakened hypercapnic ventilator drive was only demonstrated in patients with myxedema and was not responsive to hormonal therapy. ${ }^{12}$

Although previous reports have indicated the relationship between hypothyroidism and OSA and that hypothyroidism is a known risk factor for OSA, ${ }^{3,10}$ hypoventilation was overlooked in those studies, and arterial blood samples were not obtained.

In a limited number of reports with a small sample size, OSA and hypoventilation have been reported in severe hypothyroidism and myxedema. ${ }^{27,29}$ An earlier study of 26 patients with myxedema showed that hypothyroid patients had decreased ventilatory responses to hypercapnia and reduced maximal breathing capacity 
Table 2 Within-Gender Comparison Between Euthyroid, Clinical Hypothyroid, and Subclinical Hypothyroid Obesity Hypoventilation Syndrome Patients

\begin{tabular}{|c|c|c|c|c|c|c|}
\hline \multirow[t]{3}{*}{ Variable } & \multicolumn{3}{|c|}{ Mean \pm SD/n (\%) } & \multicolumn{3}{|c|}{ Mean \pm SD/n (\%) } \\
\hline & \multicolumn{3}{|l|}{ Female } & \multicolumn{3}{|l|}{ Male } \\
\hline & $\begin{array}{l}\text { Euthyroidism } \\
(n=140 \\
(70.7))\end{array}$ & $\begin{array}{l}\text { Clinical } \\
\text { Hypothyroidism } \\
(n=47(23.7))\end{array}$ & $\begin{array}{l}\text { Subclinical } \\
\text { Hypothyroidism (n } \\
=1 \mathrm{I}(7.3))\end{array}$ & $\begin{array}{l}\text { Euthyroidism } \\
(n=91(82.7))\end{array}$ & $\begin{array}{l}\text { Clinical } \\
\text { hypothyroidism } \\
(n=1 I(10))\end{array}$ & $\begin{array}{l}\text { Subclinical } \\
\text { Hypothyroidism } \\
(n=8(7.3))\end{array}$ \\
\hline Age (years) & $60.6 \pm 11.2$ & $56.6 \pm 13.6 *$ & $61 \pm 7.8$ & $45.9 \pm 13.1$ & $47.9 \pm 17.5$ & $54.8 \pm 12.2$ \\
\hline Body mass index $\left(\mathrm{kg} / \mathrm{m}^{2}\right)$ & $45.1 \pm 18.8$ & $45.7 \pm 11.1$ & $40.4 \pm 7.2$ & $41.7 \pm 9.1$ & $42.3 \pm 11.9$ & $46.4 \pm 17$ \\
\hline Neck circumference (inches) & $15.3 \pm 1.5$ & $15.6 \pm 1.5$ & $15.5 \pm 1.5$ & $16.8 \pm 1.5$ & $16.9 \pm 2.2$ & $16.4 \pm 1.4$ \\
\hline Waist circumference (inches) & $48 \pm 6.1$ & $48.7 \pm 6.5$ & $46 \pm 3.8$ & $48.9 \pm 7$ & $47.7 \pm 6.9$ & $55.1 \pm 12.2^{*}$ \\
\hline Hip circumference (inches) & $51.8 \pm 6.5$ & $54.6 \pm 7.6$ & $48.9 \pm 5.1$ & $49.9 \pm 7.7$ & $47.9 \pm 7$ & $55.1 \pm 10.3$ \\
\hline Epworth Sleepiness Scale & $10 \pm 5.7$ & $10.7 \pm 6.4$ & $9.4 \pm 5.7$ & $10.9 \pm 5.9$ & $10.5 \pm 4.5$ & $12.5 \pm 5$ \\
\hline $\mathrm{pH}$ & $7.4 \pm 0.1$ & $7.4 \pm 0$ & $7.4 \pm 0$ & $7.4 \pm 0.1$ & $7.4 \pm 0$ & $7.4 \pm 0.1$ \\
\hline $\mathrm{PaCO} 2(\mathrm{mmHg})$ & $53.6 \pm 9.1$ & $53.3 \pm 9.5$ & $53.2 \pm 8.5$ & $52.5 \pm 9.8$ & $51.5 \pm 7.2$ & $49.4 \pm 4$ \\
\hline $\mathrm{PaO} 2(\mathrm{mmHg})$ & $64.7 \pm 17$ & $64.5 \pm 15.4$ & $69.3 \pm 11.9$ & $69.6 \pm 21.8$ & $65.6 \pm 14.1$ & $74.2 \pm 23.5$ \\
\hline $\mathrm{HCO} 3(\mathrm{mmol} / \mathrm{L})$ & $31.5 \pm 5.4$ & $31.7 \pm 5.1$ & $31.8 \pm 4.9$ & $30.2 \pm 6.3$ & $29.9 \pm 2.3$ & $30.2 \pm 2.9$ \\
\hline Haematocrit & $37.6 \pm 5.5$ & $39.3 \pm 5.3$ & $39.4 \pm 3.1$ & $44.7 \pm 7.2$ & $43.5 \pm 6.9$ & $42.5 \pm 7.4$ \\
\hline TSH & $2.5 \pm 1.4$ & $4 \pm 3.4$ & $6.6 \pm 1.1 *$ & $2.2 \pm 1.1$ & $10 \pm 9.9 *$ & $7 \pm 3.7^{*}$ \\
\hline FT4: Free Thyroxine & $15.2 \pm 2.6$ & $15.3 \pm 3.4$ & $14.6 \pm 2.9$ & $14.7 \pm 2.4$ & $14.2 \pm 5.5$ & $13.2 \pm 3.5$ \\
\hline Fasting Blood Sugar & $8.1 \pm 4.6$ & $9 \pm 4.5$ & $9.1 \pm 3.5$ & $6.3 \pm 2$ & $5.5 \pm 0$ & $7 \pm 1.7$ \\
\hline \multicolumn{7}{|l|}{ Spirometry } \\
\hline $\mathrm{FEV}_{1} / \mathrm{FVC}(\%)$ & $86.7 \pm 9.8$ & $84.4 \pm 7.7$ & $86.7 \pm 7.6$ & $83.3 \pm 8$ & $78.5 \pm 14$ & $83.5 \pm 5$ \\
\hline FVC (\% predicted) & $64.5 \pm 22.5$ & $65 \pm 18.2$ & $72 \pm 18.8$ & $68.9 \pm 21.4$ & $62 \pm 21.5$ & $64.7 \pm 20.9$ \\
\hline FEV (\% predicted) & $68.7 \pm 23.9$ & $66.2 \pm 16.8$ & $75.4 \pm 18$ & $69.9 \pm 24.3$ & $58.4 \pm 21.1$ & $67.9 \pm 20.7$ \\
\hline \multicolumn{7}{|l|}{ Smoking history } \\
\hline Smoker & I (0.7) & $0(0)$ & $0(0)$ & $10(11)$ & $2(18.2)$ & $2(25)$ \\
\hline Ex-Smoker & $0(0)$ & I (2.I) & $0(0)$ & $19(20.9)$ & $2(18.2)$ & $0(0)$ \\
\hline Premenopausal & $21(15)$ & $12(25.5)$ & $2(18.2)$ & - & - & - \\
\hline \multicolumn{7}{|l|}{ Comorbidities } \\
\hline Hypertension & II 4 (8I.4) & $33(70.2)$ & $9(81.8)$ & $41(45.1)$ & $5(45.5)$ & $3(37.5)$ \\
\hline Ischaemic heart disease & $22(15.7)$ & $4(8.5)$ & I (9.1) & $10(11)$ & $2(18.2)$ & $0(0)$ \\
\hline Diabetes mellitus & $84(60)$ & $30(63.8)$ & $7(63.6)$ & $30(33)$ & $4(36.4)$ & $2(25)$ \\
\hline Renal failure & $9(6.4)$ & $4(8.5)$ & $2(18.2)$ & $3(3.3)$ & I (9.1) & $0(0)$ \\
\hline Stroke & $2(1.4)$ & $0(0)$ & $0(0)$ & $\mathrm{I}(\mathrm{I} . \mathrm{I})$ & $0(0)$ & $0(0)$ \\
\hline Bronchial asthma & $59(42.1)$ & $21(44.7)$ & $5(45.5)$ & $22(24.2)$ & $5(45.5)$ & $2(25)$ \\
\hline Hypercholesterolemia & $58(41.4)$ & $23(48.9)$ & $4(36.4)$ & $21(23.1)$ & $2(18.2)$ & $2(25)$ \\
\hline \multicolumn{7}{|l|}{ Polysomnographic findings } \\
\hline Sleep efficiency (\%) & $61.7 \pm 22.4$ & $62.2 \pm 19.6$ & $57.2 \pm 25.1$ & $68.5 \pm 20.6$ & $65.9 \pm 27$ & $75.2 \pm 19.7$ \\
\hline $\mathrm{AHI}^{\ddagger}$ (events/hr) & $59.8 \pm 44.6$ & $64.5 \pm 41.2$ & $74.7 \pm 54.9$ & $71 \pm 43.8$ & $89.6 \pm 41.8$ & $76.4 \pm 44$ \\
\hline $\mathrm{AHI} \geq 30$ & $92(65.7)$ & $35(74.5)$ & $7(63.6)$ & $69(76.7)$ & $10(90.9)$ & $8(100)$ \\
\hline AHI-NREM (events/hr) & $58 \pm 46.6$ & $64.7 \pm 42.6$ & $74.9 \pm 56$ & $70.3 \pm 46.2$ & $90.7 \pm 42.4$ & $76.9 \pm 46.1$ \\
\hline AHI-REM (events/hr) & $60.2 \pm 40.9$ & $55.6 \pm 40.2$ & $72.3 \pm 52$ & $59.8 \pm 38.3$ & $39 \pm 39.6$ & $73.7 \pm 20.3$ \\
\hline $\begin{array}{l}\text { Desaturation index } \\
\text { (desaturations/hr) }\end{array}$ & $43.5 \pm 40$ & $49.5 \pm 44.5$ & $57.5 \pm 43.9$ & $55.2 \pm 45.5$ & $52.6 \pm 43.6$ & $56 \pm 38.6$ \\
\hline Time with SpO2 <90\% (mins) & $41.1 \pm 40.2$ & $44.2 \pm 42.6$ & $54.4 \pm 43.5$ & $41.4 \pm 38.7$ & $52.6 \pm 41.9$ & $51 \pm 40.6$ \\
\hline Lowest recorded SpO2 (\%) & $71.4 \pm 17.5$ & $70.4 \pm 21.5$ & $74.1 \pm 12.9$ & $68.5 \pm 19.3$ & $70.5 \pm 10.9$ & $70.4 \pm 15.2$ \\
\hline Mean nocturnal SpO2 (\%) & $88.7 \pm 8.4$ & $87.5 \pm 11.8$ & $88.8 \pm 6.1$ & $88.3 \pm 8.8$ & $88 \pm 8.9$ & $81.4 \pm 18.1$ \\
\hline Arousal index (arousals/hr) & $60.4 \pm 40.4$ & $60.9 \pm 38.4$ & $80.1 \pm 48.1$ & $69 \pm 42$ & $77.8 \pm 41.7$ & $67 \pm 45.2$ \\
\hline
\end{tabular}

Note: ${ }^{*} p<0.05$

Abbreviations: ${ }^{\ddagger} \mathrm{AHI}$, apnoea hypopnoea index; AHI-NREM, non-rapid eye movement apnoea hypopnea index; AHI-REM, non-rapid eye movement apnoea hypopnea index. 


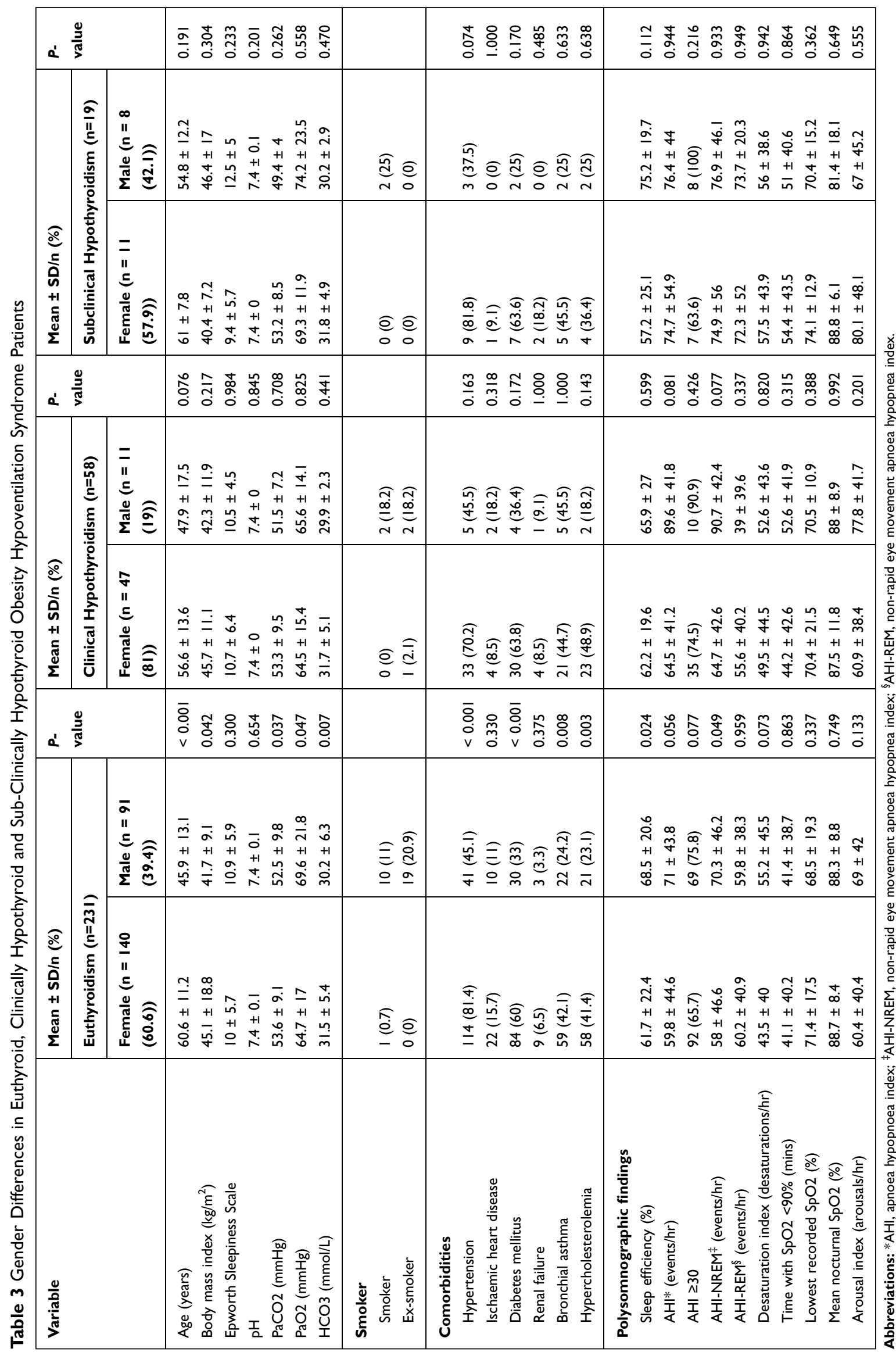


Table 4 Comparison Between Obesity Hypoventilation Syndrome Patients (OHS) and OSA Patients (OSA)

\begin{tabular}{|c|c|c|c|}
\hline \multirow[t]{2}{*}{ Variable Total $n=753$} & \multicolumn{2}{|l|}{ Mean \pm SD/n (\%) } & \multirow[t]{2}{*}{$P$-value } \\
\hline & OHS $(n=308)$ & OSA* $(n=445)$ & \\
\hline Age (years) & $55.1 \pm 13.8$ & $53.3 \pm 12.7$ & 0.052 \\
\hline Sex (Female) & $198(64.3)$ & $297(66.7)$ & 0.485 \\
\hline Body mass index $\left(\mathrm{kg} / \mathrm{m}^{2}\right)$ & $43.9 \pm 14.8$ & $41.9 \pm 7.9$ & 0.155 \\
\hline Euthyroidism & $231(75)$ & $366(82.2)$ & 0.015 \\
\hline Clinical hypothyroidism & $58(18.8)$ & $66(14.8)$ & 0.146 \\
\hline Subclinical hypothyroidism & $19(6.2)$ & $13(2.9)$ & 0.030 \\
\hline Clinical hyperthyroidism & $0(0)$ & $0(0)$ & - \\
\hline
\end{tabular}

Notes: *OSA patients matched to OHS patients in age, sex, and BMI.

(probably reflecting decreased respiratory muscle strength and endurance). ${ }^{30}$ Subsequently, Zwillich et al assessed the ventilatory response in patients with myxedema $(n=10)$ and hypothyroidism $(n=7)$ and demonstrated depressed ventilatory responses to both hypoxia and hypercapnia compared with those of euthyroid subjects $(\mathrm{n}=44) .^{12}$ Studies of the effects of thyroid hormone replacement therapy on ventilatory response had reported conflicting results; some authors showed improvement in ventilatory response, ${ }^{5,28}$ whereas others showed no improvement in respiratory parameters. ${ }^{12,30}$ In a study by Zwillich et al, introduction of thyroid hormone replacement therapy in patients with myxoedema or hypothyroidism caused no significant improvement in the hypercapnic responsiveness in either group. ${ }^{12}$ In contrast, in a study of 38 patients with hypothyroidism who were assessed after 1 week of thyroid hormone therapy, most patients normalised their ventilatory responses after 1 week of treatment. ${ }^{28}$ The discrepancy between the results of these studies suggests that the interaction between thyroid function and ventilatory response is complex, and that other factors, including the severity and duration of the hypothyroidism, may contribute to the response to thyroid hormone replacement therapy.

In the current study, none of our patients had myxoedema, they were all ambulatory, and the diagnosis of newly discovered hypothyroidism would have been missed except that in this study all patients were tested for the disorder.

The prevalence of hypothyroidism in this large sample of OHS patients was significantly higher in women with OHS compared to men with OHS. This is consistent with the reports of higher prevalence in women than in men from the general population and in OSA patients. ${ }^{8} \mathrm{~A}$ previous study in Saudi Arabia demonstrated that the prevalence of clinical hypothyroidism among women and men with OSA was $24 \%$ and $4 \%$, respectively. ${ }^{8}$

This study revealed no gender differences in OHS patients with clinical hypothyroidism. However, among euthyroid OHS patients, women were older, had a higher BMI, had a higher $\mathrm{PaCO}$, and a higher prevalence of comorbidities (hypertension, diabetes, bronchial asthma, and hypercholesterolemia). There were no differences between men with and without clinical hypothyroidism. However, for women, patients with clinical hypothyroidism were significantly younger. When we explored individual cases, we found two young patients who were diagnosed with OHS; one young patient had Down syndrome (22 years old) and one young obese patient had sickle cell disease (24 years old). When these patients were removed, the mean age of the hypothyroid women was $58.5 \pm 11.7$ years, and there was no significant difference compared with the euthyroid group.

Additionally, no significant differences were noted in BMI, blood gases, spirometry results, comorbidities, and PSG findings between euthyroid OHS patients and OHS patients with clinical hypothyroidism. This suggests that patients with clinical hypothyroidism that is treated may not essentially differ from euthyroid OHS patients in both genders (Table 2). These findings concur with those reported for OSA patients, who showed no significant differences in age, BMI, the apnoea-hypopnoea index, or the arousal index between euthyroid and hypothyroid patients. $^{8,31}$

Some of the OHS patients in this study had subclinical hypothyroidism (predominantly women), and no studies have investigated ventilatory responses in this disorder. Currently, little is known about long-term benefits of thyroid hormone replacement therapy in subclinical hypothyroidism patients in relation to survival or 
cardiovascular morbidity. ${ }^{17,32,33}$ However, thyroxine replacement may be helpful in specific settings, such as patients with hyperlipidemia and left ventricular dysfunction. ${ }^{33,34}$ But it remains to be established whether thyroid hormone replacement improves hypoventilation in those patients whose condition has not yet progressed to clinical hypothyroidism.

The reported prevalence of clinical hypothyroidism among Saudi patients with OHS in this study was higher than that reported in a previous study of Saudi patients with OSA $(18.8 \%$ vs $10 \%) .{ }^{8}$ However, the BMI of OHS patients in this study was much higher than that of the OSA patients in the previous study $\left(43.9 \pm 14.8 \mathrm{~kg} / \mathrm{m}^{2}\right.$ vs $\left.37.7 \pm 9.6 \mathrm{~kg} / \mathrm{m}^{2}\right) .{ }^{8}$ Important interactions occur between thyroid function and body weight. ${ }^{35,36}$ Data suggest that thyroid dysfunction is more common in obese subjects. ${ }^{37}$ A previous study demonstrated that among patients with obesity, $33 \%$ had overt and $11 \%$ had subclinical hypothyroidism. ${ }^{36}$ It has been reported that TSH levels are at the upper limit of normal or even slightly increased in obese subjects and are positively correlated with the BMI. $^{37}$ Therefore, measuring the TSH level alone may not be enough to diagnose hypothyroidism in OHS patients who are morbidly obese. One of the strengths of this study is that we measured both TSH and FT4 to account for this increase in TSH levels in obese subjects. This point leads us to question the accuracy of diagnosing subclinical hypothyroidism in OHS patients. Current data suggest that an elevated serum TSH level might not be sufficient to diagnose subclinical hypothyroidism in patients with morbid obesity, ${ }^{37}$ even if the FT4 level is normal. In this study, the BMI and waist circumference in men with subclinical hypothyroidism were higher than those in euthyroid men and men with clinical hypothyroidism, which raises the question if this elevation in TSH is reflecting true subclinical hypothyroidism or is related to morbid obesity. Accordingly, it would be better to measure thyroid autoantibodies to verify a diagnosis of autoimmune thyroid failure ${ }^{38}$ in future studies that aim to assess subclinical hypothyroidism in OHS patients.

As discussed previously, the prevalence of clinical hypothyroidism among Saudi patients with OHS was higher than that reported in a previous study of Saudi patients with OSA; ${ }^{8}$ however, the BMI and sex distributions were also different between these two groups. All these factors may affect the measured thyroid hormone levels. $^{36,39}$ Therefore, to assess the difference in the prevalence of clinical hypothyroidism in OHS and OSA patients while controlling for BMI, age, and gender, we compared the prevalence of clinical hypothyroidism in OHS patients with that of a group of OSA patients who were matched to the OHS patients for age, gender, and BMI. There was no significant difference in the prevalence of clinical hypothyroidism between the two groups (Table 4). However, the prevalence of subclinical hypothyroidism was higher in OHS patients despite both groups having comparable BMI. This finding complicates the understanding of the significance of subclinical hypothyroidism in OHS patients and stresses the need for further studies to assess subclinical hypothyroidism in OHS patients. Although obesity may simulate subclinical hypothyroidism, subclinical hypothyroidism was still more common in OHS patients than in a BMI-matched group of OSA patients.

This finding makes us speculate that perhaps a subset of patients with OSA and subclinical hypothyroidism may have impairment in ventilatory responses that potentially predisposes them to hypoventilation in contempt of an enhanced resistive load of OSA. ${ }^{40}$ This speculation, of course, needs confirmation.

\section{Strengths and Limitations}

The current study has strengths and limitations. Strengths include the fact that is the first study to specifically address thyroid function in OHS patients, the large sample size, that every single subject included in the study provided an arterial blood sample and underwent PSG, spirometry, and the measurement of both TSH and FT4 levels, and that measurement of TSH and FT4 levels were repeated in patients with a new diagnosis to confirm the diagnosis and to exclude patients with transient thyroid dysfunction. $^{41}$

Limitations include the observational nature of the study; second, owing to the nature of the study, we did not assess the influence of possibly impaired ventilatory responses to hypoventilation in patients with subclinical hypothyroidism compared to euthyroid patients; and third, the fact that thyroid antibodies were not measured in patients with subclinical hypothyroidism. The fact that almost all patients with hypothyroidism had normal FT4 levels at the time of referral to the sleep disorders clinic and PSG, did not allow the assessment of the acute effects of hypothyroidism on the breathing pattern in the study group. Such shortcomings should be thoroughly tackled in future studies, which will ultimately improve the generalizability and comparison of the present findings. 


\section{Conclusion}

Clinical hypothyroidism was prevalent among OHS patients. However, our results indicate that the prevalence of newly-diagnosed cases of clinical hypothyroidism is low in OHS patients, as most patients had already been diagnosed with hypothyroidism before the diagnosis of OHS to justify routine assessment for thyroid function. Clinical hypothyroidism was more prevalent among women and female sex was the only predictor of clinical hypothyroidism in OHS patients. Among patients with hypothyroidism, women were significantly older than men.

Moreover, subclinical hypothyroidism was common among patients with OHS, even after comparing it with an age-, sex-, and BMI-matched group of OSA patients. However, the clinical significance of this diagnosis and the advantages of treating this disorder is uncertain, particularly in morbidly obese subjects. Future studies should assess the ventilatory responses in OHS patients with subclinical hypothyroidism and should follow patients with subclinical hypothyroidism to assess the course of this disorder.

\section{Data Sharing Statement}

Data are available upon request. However, releasing data needs IRB approval.

\section{Ethics Statement}

The study protocol was approved the Institutional Review Board (IRB) of the College of Medicine, King Saud University and Medical City. All participants had written informed consent.

\section{Acknowledgments}

This study was supported by a grant from the "Strategic Technologies Program of the National Plan for Sciences and Technology and Innovation in the Kingdom of Saudi Arabia (08-MED511-02)".

The authors thank Prof. Shahrokh Javaheri of the Bethesda North Hospital for his help in designing the study.

\section{Author Contributions}

All authors contributed to data analysis, drafting or revising the article, have agreed on the journal (Nature and Science of Sleep) to which the article was submitted, gave final approval of the version to be published, and agree to be accountable for all aspects of the work.

\section{Disclosure}

The authors report no conflicts of interest for this work.

\section{References}

1. Vanderpump MP. The epidemiology of thyroid disease. Br Med Bull. 2011;99(1):39-51. doi:10.1093/bmb/ldr030

2. Taylor PN, Albrecht D, Scholz A, et al. Global epidemiology of hyperthyroidism and hypothyroidism. Nat Rev Endocrinol. 2018;14 (5):301-316. doi:10.1038/nrendo.2018.18

3. Schlenker EH. Effects of hypothyroidism on the respiratory system and control of breathing: human studies and animal models. Respir Physiol Neurobiol. 2012;181(2):123-131. doi:10.1016/j.resp.2012. 02.007

4. Udovcic M, Pena RH, Patham B, Tabatabai L, Kansara A. Hypothyroidism and the Heart. Methodist Debakey Cardiovasc J. 2017;13(2):55-59. doi:10.14797/mdcj-13-2-55

5. Duranti R, Gheri RG, Gorini M, et al. Control of breathing in patients with severe hypothyroidism. Am J Med. 1993;95(1):29-37. doi:10. 1016/0002-9343(93)90229-I

6. Saaresranta T, Polo O. Hormones and breathing. Chest. 2002;122 (6):2165-2182. doi:10.1378/chest.122.6.2165

7. Curnock AL, Dweik RA, Higgins BH, Saadi HF, Arroliga AC. High prevalence of hypothyroidism in patients with primary pulmonary hypertension. Am J Med Sci. 1999;318(5):289-292. doi:10.1016/ S0002-9629(15)40640-8

8. Bahammam SA, Sharif MM, Jammah AA, Bahammam AS. Prevalence of thyroid disease in patients with obstructive sleep apnea. Respir Med. 2011;105(11):1755-1760. doi:10.1016/j.rmed.20 11.07.007

9. Kuczynski W, Gabryelska A, Mokros L, Bialasiewicz P. Obstructive sleep apnea syndrome and hypothyroidism - merely concurrence or causal association? Pneumonol Alergol Pol. 2016;84(5):302-306. doi:10.5603/PiAP.2016.0038

10. Al-Jawder SE, BaHammam AS. Hypothyroidism and Obstructive Sleep Apnea. Springer D, editor. Hypothyroidism - Influences and Treatments. InTech. 2012.

11. BaHammam AS, Pandi-Perumal SR, Piper A, et al. Gender differences in patients with obesity hypoventilation syndrome. J Sleep Res. 2016;25(4):445-453. doi:10.1111/jsr.12400

12. Zwillich CW, Pierson DJ, Hofeldt FD, Lufkin EG, Weil JV. Ventilatory control in myxedema and hypothyroidism. $N$ Engl $J$ Med. 1975;292(13):662-665. doi:10.1056/NEJM197503272921302

13. BaHammam AS. Prevalence, clinical characteristics, and predictors of obesity hypoventilation syndrome in a large sample of Saudi patients with obstructive sleep apnea. Saudi Med J. 2015;36 (2):181-189. doi:10.15537/smj.2015.2.9991

14. Johns MW. Reliability and factor analysis of the Epworth Sleepiness Scale. Sleep. 1992;15(4):376-381. doi:10.1093/sleep/15.4.376

15. Miller MR, Hankinson J, Brusasco V, et al. Standardisation of spirometry. Eur Respir J. 2005;26(2):319-338. doi:10.1183/09031936. 05.00034805

16. Sanchez-Carbayo M, Mauri M, Alfayate R, Miralles C, Soria F. Analytical and clinical evaluation of TSH and thyroid hormones by electrochemiluminescent immunoassays. Clin Biochem. 1999;32 (6):395-403. doi:10.1016/S0009-9120(99)00032-6

17. Surks MI, Ortiz E, Daniels GH, et al. Subclinical thyroid disease: scientific review and guidelines for diagnosis and management. JAMA. 2004;291(2):228-238. doi:10.1001/jama.291.2.228

18. Dalal PK, Agarwal M. Postmenopausal syndrome. Indian J Psychiatry. 2015;57(Suppl 2):S222-232. doi:10.4103/0019-5545.161483

19. Berry RB, Brooks R, Gamaldo CE, et al.The AASM Manual for the Scoring of Sleep and Associated Events: Rules, Terminology and Technical Specifications, Version 2.1, Darien, Illinois: American Academy of Sleep Medicine, 2014. 
20. AASM. American Academy of Sleep Medicine (AASM). International Classification of Sleep Disorders (ICSD). 3 ed Darien, IL: AASM; 2014.

21. Devdhar M, Ousman YH, Burman KD. Hypothyroidism. Endocrinol Metab Clin North Am. 2007;36(3):595-615. doi:10.1016/j.ecl.2007. 04.008

22. Batniji RK, Cevera JJ, Gavin JP, Seymour PE, Parnes SM, Parnes SM. Supraglottic myxedema presenting as acute upper airway obstruction. Otolaryngol Head Neck Surg. 2006;134(2):348-350. doi:10.1016/j.otohns.2005.03.069

23. Watson EM, Pearce RH. The mucopolysaccharide content of the skin in localized (pretibial) myxedema. Am J Clin Pathol. 1949;19 (5):442-447. doi:10.1093/ajcp/19.5.442

24. Petrof BJ, Kelly AM, Rubinstein NA, Pack AI. Effect of hypothyroidism on myosin heavy chain expression in rat pharyngeal dilator muscles. J Appl Physiol. 1992;73(1):179-187. doi:10.1152/jappl.19 92.73.1.179

25. Pelttari L, Rauhala E, Polo O, et al. Upper airway obstruction in hypothyroidism. J Intern Med. 1994;236(2):177-181. doi:10.1111/ j.1365-2796.1994.tb01280.x

26. Simsek G, Yelmen NK, Guner I, Sahin G, Oruc T, Karter Y. The role of peripheral chemoreceptor activity on the respiratory responses to hypoxia and hypercapnia in anaesthetised rabbits with induced hypothyroidism. Chin J Physiol. 2004;47(3):153-159.

27. Massumi RAWJ, Winnacker JL. Severe depression of the respiratory center in myxedema. Am J Med. 1964;36(6):876-882. doi:10.1016/ 0002-9343(64)90117-2

28. Ladenson PW, Goldenheim PD, Ridgway EC. Prediction and reversal of blunted ventilatory responsiveness in patients with hypothyroidism. Am $J$ Med. 1988;84(5):877-883. doi:10.1016/0002-9343(88) 90066-6

29. Weg JG, Calverly JR, Johnson C. Hypothyroidism and Alveolar Hypoventilation. Arch Intern Med. 1965;115(3):302-306. doi:10.100 1/archinte. 1965.03860150046008

30. Wilson WR, Bedell GN. The pulmonary abnormalities in myxedema. J Clin Invest. 1960;39:42-55. doi:10.1172/JCI104025
31. Miller CM, Husain AM. Should women with obstructive sleep apnea syndrome be screened for hypothyroidism? Sleep Breath. 2003;7 (4):185-188. doi:10.1007/s11325-003-0185-6

32. Pham CB, Shaughnessy AF. Should we treat subclinical hypothyroidism? BMJ. 2008;337(jul16 3):290-291. doi:10.1136/bmj.a834

33. Villar HC, Saconato H, Valente O, Atallah AN. Thyroid hormone replacement for subclinical hypothyroidism. Cochrane Database Syst Rev. 2007;1(3):CD003419.

34. Nakova VV, Krstevska B, Kostovska ES, Vaskova O, Ismail LG. The effect of levothyroxine treatment on left ventricular function in subclinical hypothyroidism. Arch Endocrinol Metab. 2018;62(4):392398. doi:10.20945/2359-3997000000052

35. Laurberg P, Knudsen N, Andersen S, Carle A, Pedersen IB, Karmisholt J. Thyroid function and obesity. Eur Thyroid J. 2012;1 (3):159-167. doi:10.1159/000342994

36. Verma A, Jayaraman M, Kumar HK, Modi KD. Hypothyroidism and obesity. Cause or effect? Saudi Med J. 2008;29(8):1135-1138.

37. Sanyal D, Raychaudhuri M. Hypothyroidism and obesity: an intriguing link. Indian $J$ Endocrinol Metab. 2016;20(4):554-557. doi:10.4103/2230-8210.183454

38. Rotondi M, Leporati P, La Manna A, et al. Raised serum TSH levels in patients with morbid obesity: is it enough to diagnose subclinical hypothyroidism? Eur J Endocrinol. 2009;160(3):403-408. doi:10. 1530/EJE-08-0734

39. Yeap BB, Manning L, Chubb SA, et al. Reference Ranges for Thyroid-Stimulating Hormone and Free Thyroxine in Older Men: results From the Health In Men Study. J Gerontol a Biol Sci Med Sci. 2017;72(3):444-449. doi:10.1093/gerona/glw132

40. Rajagopal KR, Abbrecht PH, Derderian SS, et al. Obstructive sleep apnea in hypothyroidism. Ann Intern Med. 1984;101(4):491-494. doi:10.7326/0003-4819-101-4-491

41. Col NF, Surks MI, Daniels GH. Subclinical thyroid disease: clinical applications. JAMA. 2004;291(2):239-243. doi:10.1001/jama.291.2. 239

\section{Publish your work in this journal}

Nature and Science of Sleep is an international, peer-reviewed, open access journal covering all aspects of sleep science and sleep medicine, including the neurophysiology and functions of sleep, the genetics of sleep, sleep and society, biological rhythms, dreaming, sleep disorders and therapy, and strategies to optimize healthy sleep.
The manuscript management system is completely online and includes a very quick and fair peer-review system, which is all easy to use. Visit http://www.dovepress.com/testimonials.php to read real quotes from published authors. 